\title{
Rapid early weight gain is associated with wheeze and reduced lung function in childhood
}

\author{
A.C. van der Gugten*, M. Koopman*, A.M.V. Evelein\#, T.J.M. Verheij" \\ C.S.P.M. Uiterwaal ${ }^{\#}$ and C.K. van der Ent*
}

ABSTRACT: The aim of our study was to investigate the association between rapid weight gain in the first 3 months of life and the prevalence of wheeze in the first years of life and lung function at 5 yrs of age.

The infants selected were participating in an ongoing birth cohort. Information on growth and respiratory symptoms was collected during the first year of life, and on primary care consultations during total follow-up. Forced expiratory volume in $1 \mathrm{~s}$ (FEV1) and forced expiratory flow at 25$75 \%$ of forced vital capacity (FEF25-75\%) were measured at 5 yrs of age.

Information on growth and respiratory symptoms was obtained for 1,431 infants, out of whom 235 children had already had 5 yrs of follow-up. Every one-point z-score increase in weight gain resulted in a $37 \%$ increase in days with wheeze (incidence rate ratio $1.37,95 \% \mathrm{Cl} 1.27-1.47$; $\mathrm{p}<0.001$ ) and in associated consultations by $16 \%$ (incidence rate ratio $1.16,95 \% \mathrm{Cl} 1.01-1.34$; $\mathbf{p}=\mathbf{0 . 0 4 )}$. Children with rapid weight gain reported significantly more physician-diagnosed asthma. FEV1 and FEF25-75\% were reduced by $34 \mathrm{~mL}$ (adjusted regression coefficient $-\mathbf{0 . 0 3 4}$, $95 \% \mathrm{Cl}-0.056--0.013 ; \mathrm{p}=0.002$ ) and $82 \mathrm{~mL}$ (adjusted regression coefficient $-0.082,95 \% \mathrm{Cl}$ $-0.140-0.024 ; p=0.006$ ) per every one-point $z$-score increase in weight gain, respectively. These associations were independent of birthweight.

Rapid early weight gain is a risk factor for clinically relevant wheezing illnesses in the first years of life and lower lung function in childhood.

KEYWORDS: Consultations, infants, lung function, weight gain, wheezing

W heezing illnesses are highly prevalent during childhood. Almost half of all children experience wheezing during the first years of life and $\sim 10 \%$ experience asthma beyond the age of 6 yrs [1,2]. Wheezing illnesses have a major impact on children and their families [3] and account for a large number of primary healthcare consultations in the first years of life [4]. The prevalence of wheezing illnesses in affluent countries has been increasing $[5,6]$ parallel to the prevalence of obesity [7]. Although wheezing illnesses seem to be related to obesity, data in children are conflicting [8-10]. Rapid weight gain in the first years of life is a risk factor for the development of obesity [11, 12], but also for other chronic conditions, such as cardiovascular disease and type 2 diabetes [13]. It has been suggested that rapid weight gain during infancy is also a risk factor for respiratory morbidity and decreased infant lung function. In children with frequent intermittent wheezing, rapid weight gain between birth and the age of 3 yrs was associated with urgent physician visits and more frequent prednisone courses [14]. Accelerated weight gain during infancy was associated with more wheezing at the age of 3 yrs $[15,16]$, as well as in early adulthood [17]. Additionally, rapid postnatal weight gain was associated with impaired lung function development in infancy $[18,19]$.

Importantly, none of these studies focused on weight gain in the first 3 months of life, even though this may be a critical growth period. A recent study showed that rapid weight gain in the

This article has supplementary material available from www.erj.ersjournals.com

Earn CME accreditation by answering questions about this article. You will find these at the back of the printed copy of this issue or online at www.erj.ersjournals.com/site/misc/cmeinfo.xhtml

AFFILIATIONS

*Dept of Paediatric Pulmonology, Wilhelmina Children's Hospital, University Medical Center Utrecht, and

\# Julius Center for Health Sciences and Primary Care, University Medical Center Utrecht, Utrecht, The Netherlands.

CORRESPONDENCE

A.C. van der Gugten Wilhelmina Children's Hospital University Medical Center Utrecht Dept of Paediatric Pulmonology Room KH.01.419.0 P0 Box 85090 3508 AB Utrecht The Netherlands E-mail: a.c.vandergugten@ umcutrecht.nl

Received:

Dec 072010

Accepted after revision: July 172011 First published online: Aug 182011 
first 3 months of life, but not in other quarters of the first year of life, was associated with several determinants of cardiovascular disease measured in early adulthood [13]. Although the underlying mechanism responsible for the association between rapid weight gain and cardiovascular disease may differ from that of rapid weight gain and respiratory outcomes, the first 3 months after birth do seem to be a critical growth period. Moreover, previous studies have not investigated prospectively collected data on respiratory symptoms and consultations in infancy as outcomes. Furthermore, to our knowledge no study to date has shown an association between accelerated growth in the first months of life and lung function in childhood. More information on the relationships between rapid early weight gain and wheezing illnesses and lung function in healthy infants is needed to further support evidence-based patient information on feeding and growth of newborns and to reduce the burden for families and the healthcare system.

In a large prospective birth cohort of healthy infants, we studied whether rapid growth in the first 3 months of life is associated with the number of days with wheezing symptoms in the first year of life, the number of primary care consultations for wheezing in the following years and lung function in childhood.

\section{METHODS}

\section{Study design and study population}

Infants selected for this study were participating in the ongoing WHeezing Illnesses STudy LEidsche Rijn (WHISTLER), a prospective birth cohort on respiratory illnesses that started December 2001 [20]. Exclusion criteria are gestational age $<36$ weeks, major congenital abnormalities and neonatal respiratory disease. Parents of all healthy newborns in Leidsche Rijn, Utrecht, The Netherlands, with a general practitioner in one of the collaborating health centres, were asked to participate. At the age of 3-8 weeks information on pre- and post-natal risk factors was obtained by questionnaires. At the age of $5 \mathrm{yrs}$, children were invited for lung function assessment. The medical ethics committee of the University Medical Centre Utrecht, Utrecht, the Netherlands, approved the study. Written informed parental consent was obtained.

\section{Definitions of exposures and outcomes}

Birthweight and length were measured either in the hospital or by the midwife in a standardised way, by using a standard electronic scale and an infant stadiometer as used in all Dutch child healthcare centres. In the Netherlands, infants regularly visit child healthcare centres for standardised anthropometry. Anthropometrics are recorded in a personal file, which every child owns. Parents were asked to use this file to report the anthropometric measures in monthly questionnaires.

Follow-up information for wheezing during the first year of life was obtained by daily questionnaires filled in by the parents. Parents were carefully instructed by one of the investigators on how to recognise wheezing. Wheezing was defined as a positive answer to the question "Did your child wheeze (whistling sound from the chest) today?" Parents were asked to return these questionnaires on a monthly basis and, if necessary, reminders were sent.

Data on primary care visits during the first years of life was obtained from general practitioners' electronic patient files.
Physician-diagnosed wheeze was assessed using different categories of wheezing illnesses in primary care, according to the International Classification of Primary Care (ICPC) [21].

At the age of 5 yrs, information about respiratory symptoms during the previous years was assessed by a questionnaire and forced vital capacity (FVC) manoeuvres were obtained using a heated Lilly head pneumotachometer system (Viasys Healthcare, Hochberg, Germany). Measurements were body temperature, pressure and saturation (BTPS) corrected and performed conform the latest American Thoracic Society (ATS)/European Respiratory Society (ERS) statement for lung function measurements in pre-school children [22]. At least two reproducible flow-volume curves were obtained. The largest forced expiratory volume in $1 \mathrm{~s}$ (FEV1) was selected and forced expiratory flow at $25-75 \%$ of forced vital capacity (FEF25-75\%) was obtained from the curve with the highest sum of FEV1 and FVC.

In the WHISTLER project, neonatal lung function was also measured. Further details about this measurement and the association with weight gain are given in the online depository.

A positive history of parental allergy was defined as questionnaire-reported allergy to pollen, house dust mite, pets or food. Active maternal smoking during pregnancy was considered present if the mother smoked at least one cigarette per day during pregnancy. Smoke exposure after birth was defined as the child being exposed to environmental cigarette smoke for at least $2 \mathrm{~h}$ per week. Maternal higher education was defined as higher vocational or university education.

\section{Analysis}

In order to assess differences between children with and without data on growth, with and without available medical records and with and without lung function measurement at 5 yrs of age, Chi-squared tests and unpaired t-tests were used. Within the entire WHISTLER cohort, z-scores of weight were calculated at birth and at 3 months, indicating the ranks in the respective weight distributions. As not all children were weighed at exactly 3 months, the weight closest to this age was used (minimum age 60 days and maximum age 120 days) and z-scores were adjusted for the exact age in days by using linear regression. Weight gain was calculated as the difference between z-scores of weight at birth and at 3 months of age. Subsequently, rapid weight gain was defined as a change in $z$-score $>0.67$, normal weight gain as a change in z-score between -0.67 and 0.67 and slow weight gain as a change in z-score of -0.67 or less [14]. To assess possible confounding factors, baseline characteristics of groups of children with these three different weight gain patterns were tested using Chi-squared, ANOVA or Kruskal-Wallis tests where appropriate.

The number of days with wheezing symptoms between the 4th and 12th months of age was used as a count type outcome, best fitting a negative binomial distribution, as there were many children with no days of wheezing symptoms. Negative binomial regression was used, with the number of days with wheezing symptoms between the 4 th and 12th months as a dependent variable and weight gain as an independent continuous variable. The number of returned monthly questionnaires was used as an offset variable to indicate exposure time. Poisson regression was used to analyse the association between weight gain and the number of primary care consultations for wheezing illnesses in 
the groups of infants with at least 12 and 36 months of follow-up and additionally in the whole group follow-up duration in months was used as an offset variable. In order to take the dependent nature of the primary care consultations for an individual patient into account, a mixed-effects Poisson regression model was used, with a random effect for the patients and fixed effects for weight gain and other variables. Linear regression analysis was used to assess the association between weight gain in the first 3 months and FEV1 and FEF25-75\% adjusted for age and length.

For all the analyses, the crude association was first calculated. Secondly, the model was adjusted for sex and gestational age. Thirdly, the model was additionally adjusted for siblings and ethnicity of the mother, because the factors may be associated with weight gain and wheezing symptoms and lung function, and these were not equally distributed according to infants with different weight gain patterns. Although maternal smoking during pregnancy and the duration of exclusive breastfeeding were not significantly differently distributed in the groups with different weight gain patterns, these variables could be clinically relevant as they may be associated both with weight gain and wheezing symptoms and lung function; therefore the model was also adjusted for these variables.

To determine whether the association was present in children with low birthweight $(z$-score $<0)$ as well as high birthweight $(z$-score $\geqslant 0)$, the analyses were repeated after stratification according to birthweight. All the analyses were repeated with length gain as an independent continuous variable. Results are presented as incidence rate ratios (IRRs), indicating relative change in outcome rates, and linear regression coefficients, 95\% confidence intervals and p-values. Associations were considered statistically significant if $\mathrm{p}$-values were $<0.05$. Analyses were run using SPSS version 15.0 (SPSS Inc., Chicago, IL, USA) or the statistical program R (Package 2.12.2, www.R-project.org).

\section{RESULTS}

Figure 1 shows an overview of the characteristics of infants that have been included in the ongoing WHISTLER study. In $89 \%$ of the children, data on both weight gain and wheezing symptoms were obtained and in $83 \%$, data on primary care consultations were available. In $87 \%$ of the children who already had 5 yrs of follow-up, valid lung function measurements were obtained (mean \pm SD age $5.3 \pm 0.2 \mathrm{yrs}$ ). No differences were found between infants with and without data on growth, with and without information on consultations and with and without lung function measurement at $5 \mathrm{yrs}$ of age, in terms of parental allergy, gestational age, sex, siblings, maternal smoking during pregnancy, birthweight, born small for gestational age (SGA), ethnicity of the mother and exclusive breastfeeding in the first quartile (table 1). Table 2 shows baseline characteristics for different weight gain patterns. Infants with rapid weight gain were more likely to be male, born after a shorter gestation period with a lower birthweight and length, were more often SGA, were frequently born to mothers of western origin and were less likely to have siblings.

\section{Early weight gain pattern and wheezing in the first year of life}

The mean number of returned questionnaires per subject between the 4 th and 12th months was 7.8 ; in the group with

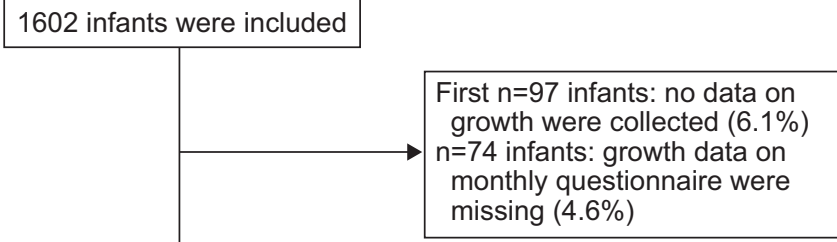

1431 infants used for analysis on effect of growth on wheezing symptoms

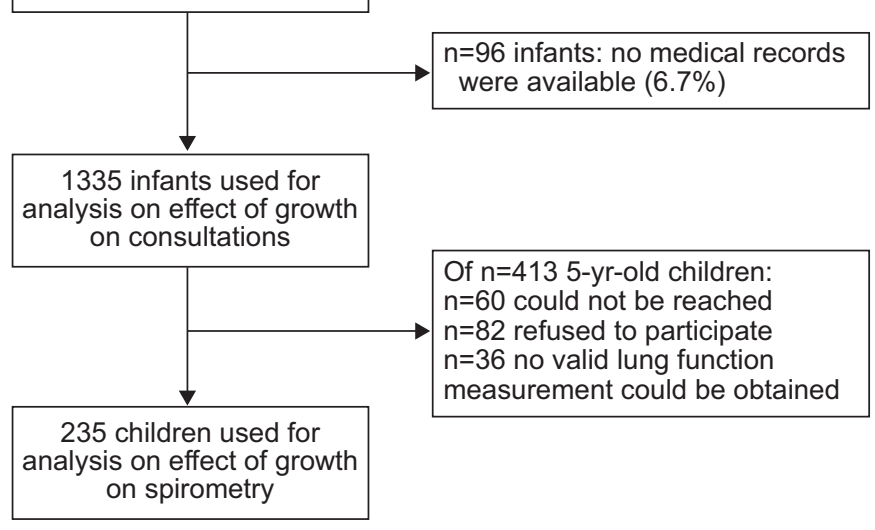

FIGURE 1. Overview of the study population.

rapid weight gain, this was 7.5. 95\% of the parents completed the questionnaires in the second quartile, $89 \%$ in the third quartile and $84 \%$ in the fourth quartile. Between the 4 th and 12 th months of the first year of life, $36 \%$ of all infants had wheezing symptoms and $15 \%$ had $>7$ days of wheezing. $21 \%$ of the children wheezed in the second quartile, $21 \%$ in the third quartile and $19 \%$ in the fourth quartile.

With increasing weight gain a higher percentage of the children wheezed (fig. 2a) and infants experienced more days with wheezing symptoms (Kruskal-Wallis test $p=0.001$ ) (fig. $2 b$ ). Table 3 shows a $37 \%$ higher rate of days with wheezing symptoms per one-point z-score increase in weight gain, after adjustment for sex, gestational age and other potential confounders. Significant associations were found within children with low or high birthweight (IRR 1.29, 95\% CI 1.16-1.43, $\mathrm{p}<0.001$; versus IRR 1.48, 95\% CI 1.33-1.64, $\mathrm{p}<0.001$; respectively). No significant association was found between gain in length and days with wheezing symptoms, after adjustment for confounders (IRR 1.05, 95\% CI 0.96-1.15; p=0.221).

\section{Early weight gain pattern and primary care consultations for wheezing illnesses until the age of 5 yrs}

Median follow-up time for primary care consultations was 38.2 months (range 1-91); 1,217 infants had $\geqslant 1$ yr of follow-up, and 711 infants $\geqslant 3$ yrs. $25.2 \%$ of all infants had at least one primary care consultation for wheezing illnesses during the first year of life, $39.7 \%$ of all infants during the first 3 yrs of life, and $47.5 \%$ during the first 5 yrs of life. Table 3 shows that a one-point $z$-score increase in weight gain was related to a $26 \%$ higher rate of primary care consultations for wheezing illnesses in the first year of life, a $23 \%$ higher rate in the group of children with 3 yrs of follow-up, and a 16\% higher rate in the total group, accounting for follow-up duration. Stratification according to birthweight 
TABLE 1 General characteristics of the different subgroups that were studied

\begin{tabular}{|c|c|c|c|c|}
\hline & Total group & $\begin{array}{l}\text { Group with complete growth } \\
\text { data and daily symptoms }\end{array}$ & $\begin{array}{l}\text { Group with complete growth } \\
\text { data and medical records }\end{array}$ & $\begin{array}{l}\text { Group with lung function } \\
\text { measurement at age } 5 \mathrm{yrs}\end{array}$ \\
\hline Subjects $\mathbf{n}$ & 1602 & 1431 & 1335 & 235 \\
\hline Male \% & 49.3 & 48.6 & 49.5 & 45.3 \\
\hline Mean birthweight $\mathrm{g}$ & 3525 & 3525 & 3529 & 3503 \\
\hline Mean gestational age days & 278.6 & 278.6 & 278.7 & 279.2 \\
\hline Paternal allergy \% & 37.5 & 37.2 & 38.1 & 38 \\
\hline Exclusive breastfeeding median weeks & 6.4 & 6.9 & 6.3 & 6.1 \\
\hline Having at least one sibling $\%$ & 51.8 & 52.5 & 50.7 & 49.8 \\
\hline Maternal smoking during pregnancy $\%$ & 5.9 & 5.6 & 5.7 & 6.9 \\
\hline Ethnicity mother \% western & 90.1 & 90.7 & 89.6 & 90.5 \\
\hline
\end{tabular}

SGA: small for gestational age. ${ }^{\#}$ : weight for gestational age <10th percentile; ": allergy to pollen, house dust mite, food or pets. No significant differences between the total group and different subgroups were found (data not shown).

TABLE 2 Baseline characteristics of total study population by growth pattern

\begin{tabular}{|c|c|c|c|c|c|}
\hline & \multirow[t]{2}{*}{ Total group } & \multicolumn{3}{|c|}{ Weight gain ${ }^{\#}$} & \multirow[t]{2}{*}{ p-value } \\
\hline & & Slow & Normal & Rapid & \\
\hline Males \% & 48.6 & 31.7 & 47.4 & 69.3 & $<0.001^{5}$ \\
\hline Mean birthweight g & 3525 & 3859 & 3500 & 3237 & $<0.001^{f}$ \\
\hline Mean birth length $\mathrm{cm}$ & 50.9 & 51.9 & 50.9 & 50.0 & $<0.001^{f}$ \\
\hline Mean length at day $90 \mathrm{~cm}$ & 61.1 & 61.1 & 61.0 & 61.4 & $0.119^{f}$ \\
\hline Mean gestational age days & 278.6 & 282.1 & 278.8 & 274.5 & $<0.001^{f}$ \\
\hline SGA \% & 9.6 & 3.0 & 7.9 & 20.7 & $<0.001^{\S}$ \\
\hline Maternal asthma in last 12 months \% & 9.2 & 7.6 & 10.0 & 9.0 & $0.493^{\S}$ \\
\hline Maternal allergy ${ }^{+} \%$ & 38.6 & 35.0 & 39.2 & 41.0 & $0.313^{\S}$ \\
\hline Paternal asthma in last 12 months \% & 6.4 & 5.8 & 6.1 & 7.7 & $0.632^{\S}$ \\
\hline Having at least one sibling $\%$ & 52.5 & 59.2 & 50.3 & 50.6 & $0.019^{\S}$ \\
\hline Pet ownership during pregnancy $\%$ & 40.4 & 38.5 & 40.4 & 42.4 & $0.585^{\S}$ \\
\hline Pet ownership after birth \% & 39.6 & 36.9 & 39.5 & 42.6 & $0.337^{\S}$ \\
\hline Maternal smoking during pregnancy $\%$ & 5.6 & 4.7 & 5.6 & 6.5 & $0.613^{\S}$ \\
\hline Smoke exposure after birth \% & 12.3 & 12.1 & 13.2 & 10.9 & $0.798^{\S}$ \\
\hline Maternal higher education \% & 66.5 & 69.3 & 65.6 & 65.8 & $0.527^{\S}$ \\
\hline Birth season \% & & & & & $0.792^{\S}$ \\
\hline Winter & 22.8 & 23.1 & 23.0 & 22.0 & \\
\hline Spring & 25.4 & 24.3 & 24.9 & 27.6 & \\
\hline Summer & 26.8 & 29.0 & 25.7 & 27.2 & \\
\hline
\end{tabular}

SGA: small for gestational age. ${ }^{\#}$ : categories of weight gain are given as the change $(\Delta)$ in weight z-scores between birth and 3 months: slow weight gain corresponds to a $\Delta$ z-score $<-0.67$, normal weight gain to a $\Delta z$-score of $\geqslant-0.67$ and $<0.67$, and rapid weight gain to a $\Delta z$-score of $\geqslant 0.67$; ": weight for gestational age $<10$ th percentile; ${ }^{+}$: allergy to pollen, house dust mite, food or pets; ${ }^{\text {s }}$ : Chi-squared test; ${ }^{f}$ : ANOVA test; ${ }^{\# \#}$ : Kruskal-Wallis test. p-values in bold are statistically significant. 


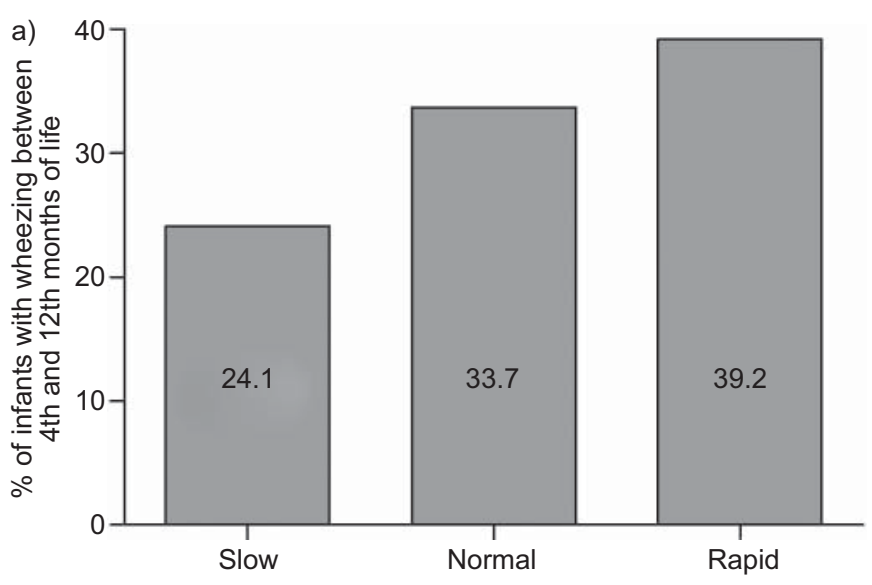

Weight gain in first 3 months of life

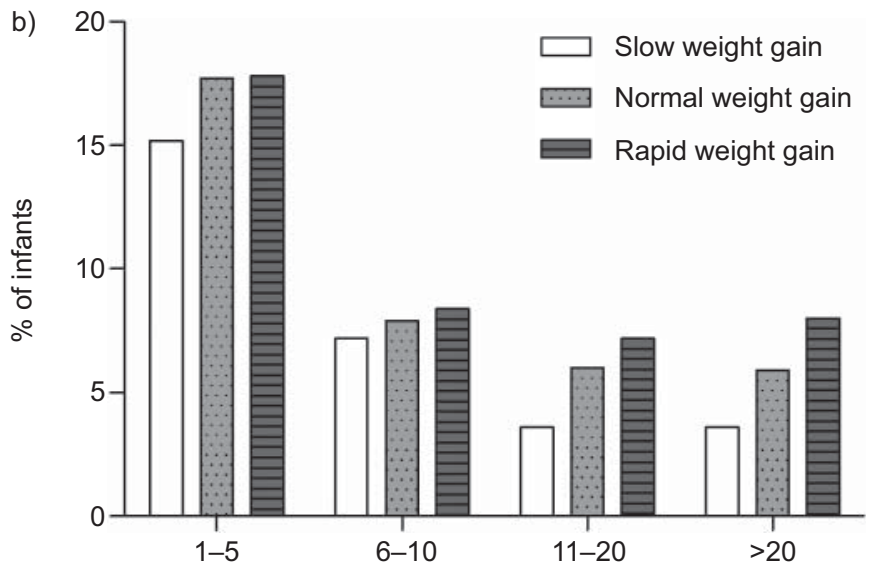

Days with wheezing between 4th and 12th months of life

FIGURE 2. a) Percentage of children with wheezing complaints and b) the number of wheezing complaints in the 4th to 12th months of life per weight gain category. Categories of weight gain are given as the change $(\Delta)$ in weight $z$-scores between birth and 3 months: slow weight gain corresponds to a $\Delta z$-score $<-0.67$, normal weight gain to a $\Delta z$-score of $\geqslant-0.67$ and $<0.67$, and rapid weight gain to a $\Delta z$-score of $\geqslant 0.67$. In a), Chi-squared test $p<0.001$.

did not materially influence the results, and no significant association was found between length gain and primary care consultations for wheezing illnesses (data not shown).

\section{Early weight gain pattern and wheeze and lung function at the age of 5 yrs}

Of the 5-yr-old children with rapid weight gain, 32.1\% reported wheezing over the last 12 months, which was significantly more often than the children with normal $(7.7 \%)$ or slow $(19.0 \%)$ weight gain (Chi-squared $p=0.020)$. Furthermore, they reported to have had a physician's diagnosis of asthma significantly more frequently $(18.2 \%$ versus $3.3 \%$ and $3.5 \%$, respectively; Chi-squared $\mathrm{p}=0.001)$. Mean FEV1 at the age of 5 yrs was $1.280 \pm 0.177 \mathrm{~L}$ and mean FEF25-75\% was $1.502 \pm 0.386$ L. Table 4 shows that after adjustment for confounders, a one-point z-score increase in weight gain was associated with a significant decrease in FEV1 $(-34 \mathrm{~mL}(-2.7 \%))$ and a significant decrease in FEF25-75\% $(-82 \mathrm{~mL}$ $(-5.4 \%))$. After stratification according to birthweight, the same associations were found in both groups (table 4). No significant association was found between gain in length and lung function (data not shown).
Results on the association between weight gain and neonatal lung function measurement are given in the online supplementary material.

\section{DISCUSSION}

Our study shows that rapid weight gain in the first 3 months after birth is associated with clinically relevant wheezing illnesses in the first years of life and a decreased lung function at 5 yrs of age, and that this association is independent of birthweight.

In our cohort, wheezing complaints were prospectively documented only during the first year of life. Primary care consultations were obtained for the total follow-up period. The association between rapid weight gain and primary care consultations seemed to be somewhat stronger in the first year than in the following years, suggesting that the effect diminishes with increasing age. One explanation could be that, at an older age, other factors play an increasingly important role in wheezing symptoms and consultations. Follow-up of our cohort will determine whether the effect of rapid weight gain on respiratory symptoms persists or disappears during childhood, relative to other causes. Nevertheless, in the 5-yr-old subgroup that experienced rapid weight gain in the first 3 months of life, a significantly higher percentage reported wheezing over the last 12 months and a physicians' diagnosis of asthma.

Only a few studies have investigated the relationship between rapid growth and wheezing symptoms [14-17]. Although these studies investigated different domains and different periods of weight gain and outcome, they showed similar results. Our results are also in accordance with studies showing decreased lung function after rapid post-natal growth [18, 19]. To our knowledge, to date, only one study has analysed the association between rapid weight gain and childhood spirometry, but it was unable to show a significant association [18].

Several mechanisms may be responsible for our findings. According to the hypothesis of BARKER et al. [23], chronic conditions later in life are due to an unfavourable fetal environment, with retarded growth in utero and compensatory growth after birth. Later studies showed that especially rapid compensatory growth seems to be a risk factor for unfavourable future health-related outcomes, such as hypertension and obesity $[24,25]$. In our study, the children in the group with rapid weight gain had a lower birthweight and there was a higher prevalence of infants born SGA. However, we found that the association was present in both subgroups after stratification according to birthweight. Independent of baseline weight, rapid weight gain has a negative effect on outcome. The "mismatch hypothesis" proposes that especially the difference between the fetal environment and the environment after birth could result in diseases later in life [26]. Another possible explanation is chronic inflammation. Obesity can be seen as a state of chronic, lowgrade, systemic inflammation. Contrary to rapid length gain, rapid weight gain was specifically associated with wheezing symptoms. Although not all children with rapid weight gain were obese, there was acquisition of adipose tissue. Adipokines, chemokines and other serum factors from adipose tissue could lead to inflammation at other sites [27], such as the airways, leading to wheezing complaints. Since small airways and viral infections play an important role in wheezing in the first years of life [1], our findings may also be explained by disproportional 


\begin{tabular}{|c|c|c|c|c|c|}
\hline \multirow{4}{*}{\multicolumn{2}{|c|}{ TABLE 3}} & st 3 months of & lays witl & g symptoms or $\mathrm{n}$ & -associated \\
\hline & & \multicolumn{4}{|c|}{ Weight gain ${ }^{\#}$ (per one-point z-score increase) } \\
\hline & & \multicolumn{2}{|c|}{ Crude } & \multicolumn{2}{|c|}{ Adjusted } \\
\hline & & IRR (95\% CI) & p-value & IRR $(95 \% \mathrm{Cl})$ & $\mathrm{p}$-value \\
\hline \multicolumn{2}{|c|}{$\begin{array}{l}\text { Days with wheezing symptoms during months } \\
4-12 \text { (number of monthly questionnaires is offset) }\end{array}$} & & & $1.37(1.27-1.47)^{\bullet}$ & $<0.001$ \\
\hline \multicolumn{6}{|c|}{ Primary care visits for wheezing illnesses } \\
\hline \multirow{2}{*}{\multicolumn{2}{|c|}{ In first year of life ${ }^{+}$}} & $1.33(1.12-1.16)$ & 0.002 & $1.26(1.03-1.53)^{\# \#}$ & 0.02 \\
\hline & & & & $1.26(1.03-1.53)^{\pi}$ & 0.02 \\
\hline \multicolumn{2}{|c|}{ In first 3 yrs of life $e^{\S}$} & $1.29(1.09-1.54)$ & 0.003 & $1.22(1.01-1.47)^{\# \#}$ & 0.04 \\
\hline
\end{tabular}

IRR: incidence rate ratio. ${ }^{\#}$ : differences between $\mathrm{z}$-score for weight at age 3 months (adjusted for the exact age in days) and at birth; ${ }^{\bullet}: \mathrm{n}=1431 ;{ }^{+}: \mathrm{n}=1217 ;{ }^{\text {s }}: \mathrm{n}=711$; $f: n=1335 ;$;\#: adjusted for sex and gestational age; $"$ : also adjusted for other potential confounders (maternal smoking during pregnancy, duration of exclusive breastfeeding, siblings and the ethnicity of the mother). p-values in bold are statistically significant.

growth. A rapid increase of weight may cause lung development to lag behind somatic growth. The association between rapid weight gain and reduced neonatal lung function shows that the effect is already present in early infancy. As neonatal lung function is associated with later wheezing symptoms, one could expect neonatal lung function to be an intermediate in the causal chain. However, adjustment for neonatal lung function did not significantly influence the association.

Although the mechanism is not completely clear, the results of this study may have implications for clinical practice. Although not all wheezing illnesses will develop into asthma, we believe that an improved control of weight gain and the reduction of unnecessary rapid weight gain could help to diminish the burden of wheezing illnesses in children and their families, and the associated burdens to primary healthcare.

The strength of this study is the large sample size of healthy newborns and the prospective and standardised manner in which data were collected. Data on wheezing symptoms were collected on a daily basis and we were able to adjust for the most important confounders. However, some methodological considerations should be made. First, information on wheezing symptoms was obtained from questionnaires with

\section{TABLE 4 Association between weight gain in the first 3 months of life and lung function at 5 yrs of age}

\begin{tabular}{|c|c|c|c|c|}
\hline \multirow{2}{*}{$\begin{array}{l}\text { Weight gain }{ }^{\#} \text { (per one-point } \\
\text { z-score increase) }\end{array}$} & \multicolumn{2}{|c|}{ Crude } & \multicolumn{2}{|l|}{ Adjusted } \\
\hline & Regression coefficient & p-value & Regression coefficient $(95 \% \mathrm{Cl})$ & p-value \\
\hline \multirow[t]{2}{*}{ Total group } & $-0.025(-0.044--0.005)$ & 0.014 & $-0.035^{\S}(-0.056--0.013)$ & 0.002 \\
\hline & & & $-0.034^{f}(-0.056--0.013)$ & 0.002 \\
\hline Birthweight $<0$ z-score & & & $-0.024^{f}(-0.060-0.013)$ & 0.2 \\
\hline \multicolumn{5}{|l|}{ FEF $25-75 \%{ }^{\tau_{0}+} L \cdot S^{-1}$} \\
\hline \multirow[t]{2}{*}{ Total group } & $-0.059(-0.111--0.008)$ & 0.024 & $-0.079^{\S}(-0.136--0.023)$ & 0.006 \\
\hline & & & $-0.082^{f}(-0.140--0.024)$ & 0.006 \\
\hline Birthweight $<0$ z-score & & & $-0.062^{f}(-0.160-0.037)$ & 0.216 \\
\hline Birthweight $>0$ z-score & & & $-0.085^{f}(-0.177-0.008)$ & 0.073 \\
\hline
\end{tabular}

FEV1: forced expiratory volume in $1 \mathrm{~s}$; FEF25-75\%: forced expiratory flow at 25-75\% of forced vital capacity. ${ }^{*}$ : Differences between z-score for weight at 3 months of age

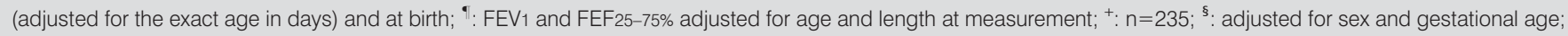
$f$ : also adjusted for other potential confounders (maternal smoking during pregnancy, duration of exclusive breastfeeding, siblings, and the ethnicity of the mother). p-values in bold are statistically significant. 
parent-reported symptoms, which may be misclassified due to confusion about the distinction between wheeze and snoring or cough [28]. We minimised this by careful parental instruction and the percentage of children with wheezing complaints was similar to other studies $[29,30]$. More importantly, the possible misclassification is probably nondifferential, and therefore unrelated to weight gain pattern. Secondly, not all parents completed all monthly questionnaires during the first year of life of their child, and this was slightly lower even for the group with rapid weight gain compared with the other weight-gain groups. In most instances, the last questionnaires were missing. The number of returned questionnaires was used as offset in the analysis. Due to the fact that the prevalence of wheezing symptoms was comparable during different quartiles of the first year of life, the missing questionnaires would probably not have influenced the association. At the time of analysis, only a subgroup of the children in our study population had already reached the age of 5 yrs. As this subgroup had the same characteristics as the total cohort and was representative of the total cohort, we considered the significant association between weight gain and lung function in this subgroup as a valuable addition to the other results. Thirdly, it was not possible to adjust for respiratory infections because we were not able to differentiate wheezing illnesses, with and without respiratory infections, from the monthly questionnaires and from the primary care consultations. However, in young children, wheezing illnesses are frequently associated with respiratory infections. In a previous study, we showed that in almost all respiratory episodes in infants, one or more respiratory pathogens were detected [31]. Fourthly, we calculated z-scores based on our own population, instead of using age-related, sex-specific growth charts. The mean birthweight and weight at 3 months are comparable to the average weights according to (inter)national growth charts $[32,33]$. Moreover, the relevance of our findings pertains to within-group relative growth patterns and, when using international growth charts to calculate z-scores, the same results were found. Weight gain was initially not adjusted for sex and gestational age, and therefore boys are over-represented in the rapid weight gain group. Sex is associated with weight gain and with wheezing illnesses, and this variable was therefore taken into account as a potential confounder in the multivariate regression, instead of only adjusting weight gain for sex. Fifthly, the percentage of mothers that smoked during pregnancy in our cohort is quite low, compared with other cohort studies. However, the rates of maternal smoking throughout pregnancy have decreased significantly in the Netherlands during recent decades, to $7.6 \%$ in 2007 [34]. As smoking during pregnancy is associated with reduced birthweight and increased wheezing symptoms, it could be a confounder. After adjustment for maternal smoking during pregnancy, the results did not change. However, other results might be found in populations with a higher prevalence of maternal smoking during pregnancy. Lastly, measuring lung function at the age of 5 yrs is difficult. However, the measurements were performed by experienced lung-function analysts according to the latest ATS/ERS statement and were successful in a majority of the children.

In conclusion, this study showed that rapid early post-natal weight gain is associated with an increased incidence of parental-reported and physician-diagnosed wheezing illnesses in the first years of life and reduced lung function at 5 yrs of age.

\section{SUPPORT STATEMENT}

The WHISTLER study is supported by grants from the Netherlands Organisation for Health Research and Development (ZON-MW), by the University Medical Center Utrecht and by an unrestricted research grant from GlaxoSmithKline, the Netherlands. The funding agencies did not have any role in the study design, data collection, analysis and interpretation of data, or in the writing of the article and the decision to submit it for publication. All researchers are independent from funding agencies.

\section{STATEMENT OF INTEREST}

A statement of interest for all authors of this manuscript can be found at www.erj.ersjournals.com/site/misc/statements.xhtml

\section{ACKNOWLEDGEMENTS}

The authors thank all the parents and children who participated, R. Bekkema and L. van der Feltz-Minkema (Dept of Paediatric Pulmonology, Wilhelmina Children's Hospital, University Medical Center Utrecht, Utrecht, the Netherlands) for their assistance in recruiting the subjects and collecting the data, and M. Olling-de Kok for her secretarial assistance (Dept of Paediatric Pulmonology, Wilhelmina Children's Hospital).

\section{REFERENCES}

1 Martinez FD, Wright AL, Taussig LM, et al. Asthma and wheezing in the first six years of life. The Group Health Medical Associates. N Engl J Med 1995; 332: 133-138.

2 Matricardi PM, Illi S, Grüber C, et al. Wheezing in childhood: incidence, longitudinal patterns and factors predicting persistence. Eur Respir J 2008; 32: 585-592.

3 Mohangoo AD, Essink-Bot ML, Juniper EF, et al. Health-related quality of life in preschool children with wheezing and dyspnea: preliminary results from a random general population sample. Qual Life Res 2005; 14: 1931-1936.

4 Stevens CA, Turner D, Kuehni CE, et al. The economic impact of preschool asthma and wheeze. Eur Respir J 2003; 21: 1000-1006.

5 Kuehni CE, Davis A, Brooke AM, et al. Are all wheezing disorders in very young (preschool) children increasing in prevalence? Lancet 2001; 357: 1821-1825.

6 Asher MI, Montefort S, Bjorksten B, et al. Worldwide time trends in the prevalence of symptoms of asthma, allergic rhinoconjunctivitis, and eczema in childhood: ISAAC Phases One and Three repeat multicountry cross-sectional surveys. Lancet 2006; 368: 733-743.

7 Van Cleave J, Gortmaker SL, Perrin JM. Dynamics of obesity and chronic health conditions among children and youth. JAMA 2010; 303: 623-630.

8 Schachter LM, Peat JK, Salome CM. Asthma and atopy in overweight children. Thorax 2003; 58: 1031-1035.

9 Scholtens S, Wijga AH, Seidell JC, et al. Overweight and changes in weight status during childhood in relation to asthma symptoms at 8 years of age. J Allergy Clin Immunol 2009; 123: 1312-1318.

10 Chinn S, Downs SH, Anto JM, et al. Incidence of asthma and net change in symptoms in relation to changes in obesity. Eur Respir J 2006; 28: 763-771.

11 Baird J, Fisher D, Lucas P, et al. Being big or growing fast: systematic review of size and growth in infancy and later obesity. BMJ 2005; 331: 929.

12 Hui LL, Schooling CM, Leung SS, et al. Birth weight, infant growth, and childhood body mass index: Hong Kong's children of 1997 birth cohort. Arch Pediatr Adolesc Med 2008; 162: 212-218.

13 Leunissen RW, Kerkhof GF, Stijnen T, et al. Timing and tempo of first-year rapid growth in relation to cardiovascular and metabolic risk profile in early adulthood. JAMA 2009; 301: 2234-2242.

14 Paul IM, Camera L, Zeiger RS, et al. Relationship between infant weight gain and later asthma. Pediatr Allergy Immunol 2010; 21: 82-89. 
15 Taveras EM, Rifas-Shiman SL, Camargo CA Jr, et al. Higher adiposity in infancy associated with recurrent wheeze in a prospective cohort of children. J Allergy Clin Immunol 2008; 121: 1161-1166.

16 Pike KC, Crozier SR, Lucas JS, et al. Patterns of fetal and infant growth are related to atopy and wheezing disorders at age 3 years. Thorax 2010; 65: 1099-1106.

17 Rona RJ, Smeeton NC, Bustos P, et al. The early origins hypothesis with an emphasis on growth rate in the first year of life and asthma: a prospective study in Chile. Thorax 2005; 60: 549-554.

18 Turner S, Zhang G, Young S, et al. Associations between postnatal weight gain, change in postnatal pulmonary function, formula feeding and early asthma. Thorax 2008; 63: 234-239.

19 Lucas JS, Inskip HM, Godfrey KM, et al. Small size at birth and greater postnatal weight gain: relationships to diminished infant lung function. Am J Respir Crit Care Med 2004; 170: 534-540.

20 Katier N, Uiterwaal CS, De Jong BM, et al. The Wheezing Illnesses Study Leidsche Rijn (WHISTLER): rationale and design. Eur J Epidemiol 2004; 19: 895-903.

21 Verbeke M, Schrans D, Deroose $S$, et al. The International Classification of Primary Care (ICPC-2): an essential tool in the EPR of the GP. Stud Health Technol Inform 2006; 124: 809-814.

22 Beydon N, Davis SD, Lombardi E, et al. An official American Thoracic Society/European Respiratory Society statement: pulmonary function testing in preschool children. Am J Respir Crit Care Med 2007; 175: 1304-1345.

23 Barker DJ, Gluckman PD, Godfrey KM, et al. Fetal nutrition and cardiovascular disease in adult life. Lancet 1993; 341: 938-941.
24 Stettler N, Zemel BS, Kumanyika S, et al. Infant weight gain and childhood overweight status in a multicenter, cohort study. Pediatrics 2002; 109: 194-199.

25 Singhal A, Cole TJ, Fewtrell M, et al. Promotion of faster weight gain in infants born small for gestational age: is there an adverse effect on later blood pressure? Circulation 2007; 115: 213-220.

26 Pike KC, Hanson MA, Godfrey KM. Developmental mismatch: consequences for later cardiorespiratory health. BJOG 2008; 115: 149-157.

27 Shore SA. Obesity and asthma: possible mechanisms. J Allergy Clin Immunol 2008; 121: 1087-1093.

28 Cane RS, Ranganathan SC, McKenzie SA. What do parents of wheezy children understand by "wheeze"? Arch Dis Child 2000; 82: 327-332.

29 Wright RJ, Cohen S, Carey V, et al. Parental stress as a predictor of wheezing in infancy: a prospective birth-cohort study. Am J Respir Crit Care Med 2002; 165: 358-365.

30 Visser CA, Garcia-Marcos L, Eggink J, et al. Prevalence and risk factors of wheeze in Dutch infants in their first year of life. Pediatr Pulmonol 2010; 45: 149-156.

31 van der Zalm MM, Uiterwaal CS, Wilbrink B, et al. Respiratory pathogens in respiratory tract illnesses during the first year of life: a birth cohort study. Pediatr Infect Dis J 2009; 28: 472-476.

32 WHO Child Growth Standards based on length/height, weight and age. Acta Paediatr Suppl 2006; 450: 76-85.

33 Gerver WJM, de Bruin R. Paediatric Morphometrics. A Reference Manual. 2nd Edn. Maastricht, Universitaire Pers Maastricht, 2001.

34 Lanting CI, Buitendijk SE, Crone MR, et al. Clustering of socioeconomic, behavioural, and neonatal risk factors for infant health in pregnant smokers. PLoS One 2009; 4: e8363. 